\title{
南极中山站极夜和极昼期间的辐射特征 ${ }^{*}$
}

\author{
陆龙䯅 六林根 贾朋群 \\ (中国气象科学研究院极地气象研究室,北京 100081)
}

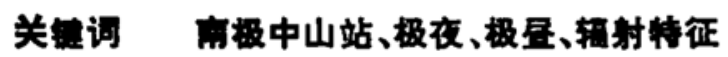

极夜和极昼是地球上南北极圈内出现的太阳终日不出和终日不落的特殊现象. 我国南极 长城站 $\left(62^{\circ} 13^{\prime} \mathrm{S}, 58^{\circ} 58^{\prime} \mathrm{W}\right)$ 无极夜和极昼; 中山站 $\left(69^{\circ} 22^{\prime} \mathrm{S}, 76^{\circ} 22^{\prime} \mathrm{E}\right)$ 有 58 天极夜和 55 天 极昼期. 1990 年 2 月至 1991 年 1 月, 我国在南极中山站进行了辐射和热状况观测实验 ${ }^{[1]}$, 为 本文研究提供了条件.

\section{一、中山站的极夜和极量}

在中山站地区, 1990-1991年度的极夜期为 5 月 24 日至 7 月 20 日，极昼期为 11 月 25 日 至 1 月 18 日.在夏至日( 12 月 22 日), 中山站地方时正午及子夜的太阳高度角分别为 $44^{\circ} 04^{\prime}$ 及 $2^{\circ} 49^{\prime}$.

图 1 给出了1989 年 1 月 1 日我国 “极地号”科学考察船在中山站附近海区 $\left(69^{\circ} 10^{\prime} \mathrm{S}\right.$, $76^{\circ} 00^{\prime} \mathrm{E}$ ) 时测得的全天太阳方位和高度. 由图 1 可见, 子夜时太阳方位在正南, 高度角为

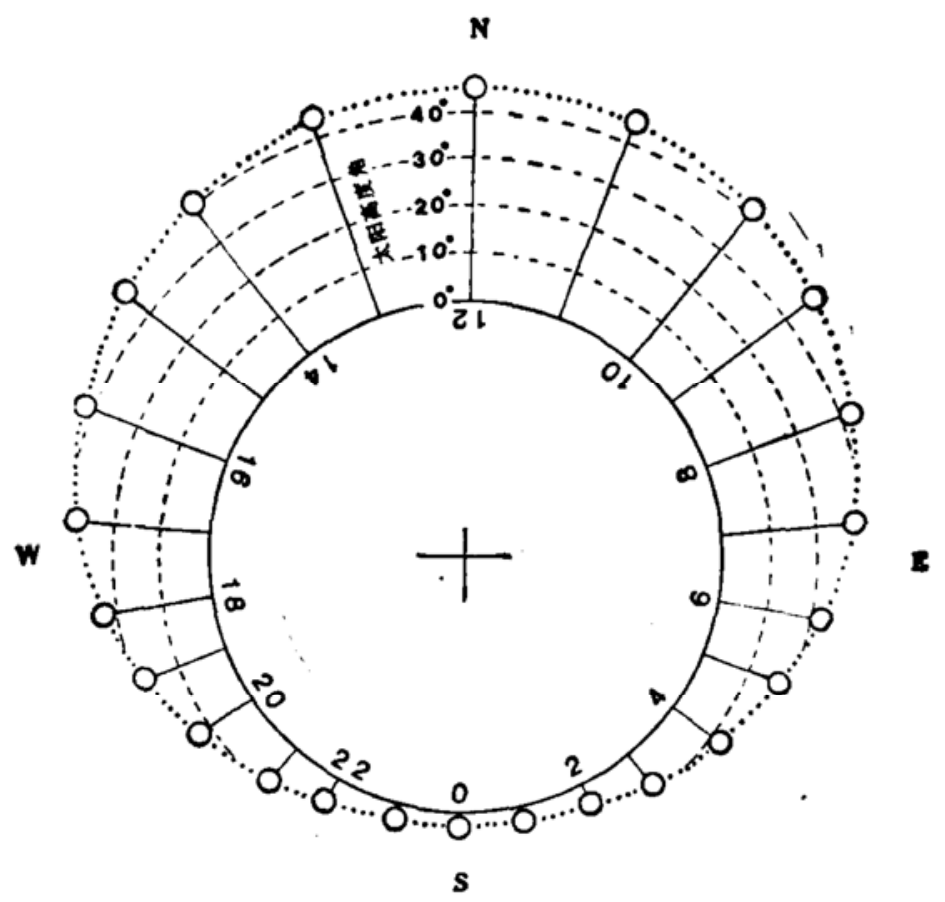

图11989年1月1日中山站附近的太阳方位角和高度角(地方时)

1992-01-16 收植, 1992-04-23 收皆改稍

- 国家自然科学企全和南极考察委员会资助项目 

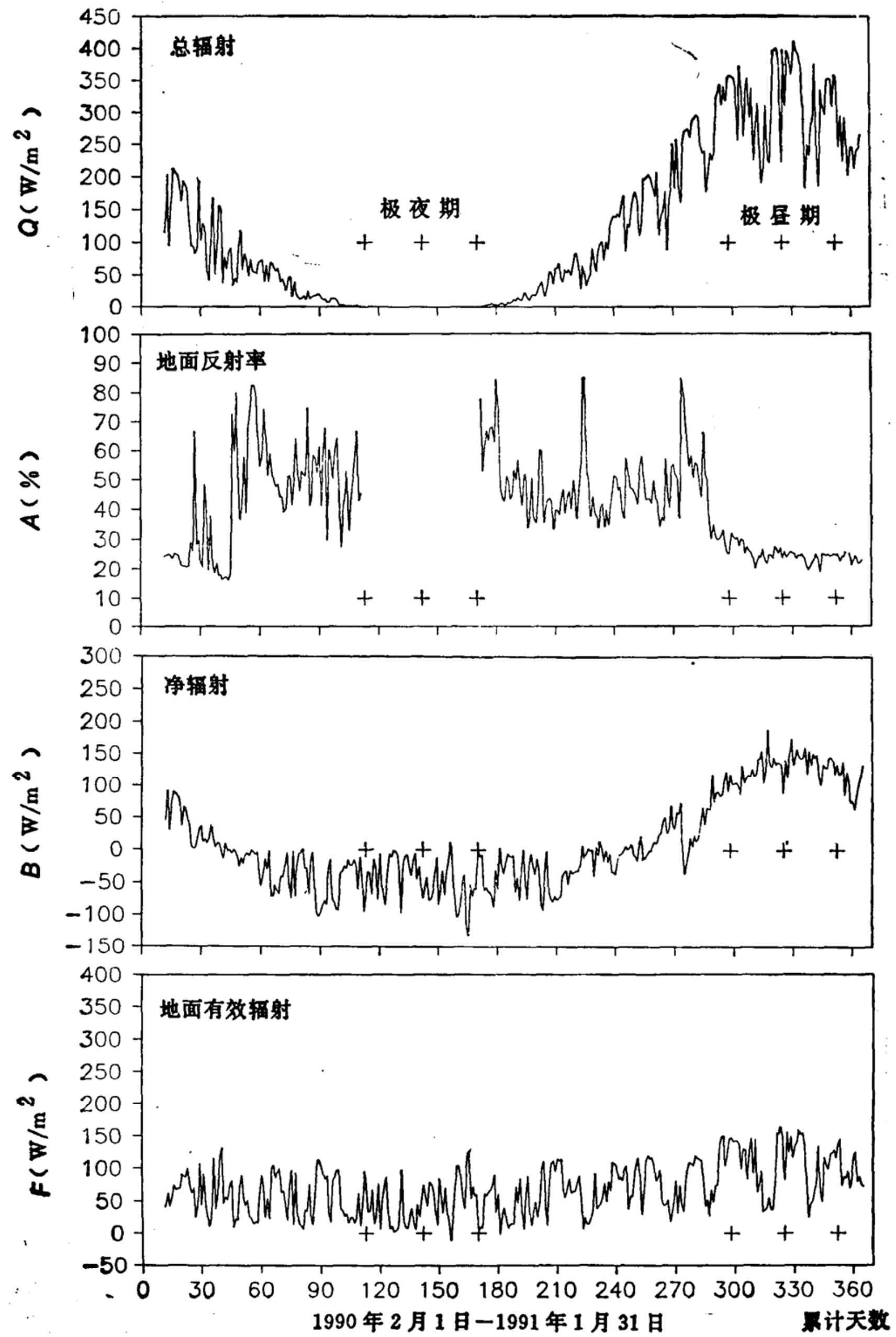

图 2 中山站辐射特征的年变化 
$2^{\circ} 06^{\prime}$, 正午时太阳在正北, 高度角 $43^{\circ} 42^{\prime}$. 一一天内太阳在天边由南一东一北一西一南, 逆时针 运行一周. 极夜和极昼期的时间随纬度增高而加长, 在极点有半年极夜和半年极昼期, 且在夏 至日,全日太阳高度角保持不变,均为 $23^{\circ} 27^{\prime}$ 。

\section{二、中山站极夜和极昼期间的辐射特征}

\section{1. 总喓射 $Q$ 和地面吸收辐射 $Q(1-A)$}

图 2 给出了中山站 1990 年 2 月 1 日至 1991 年 1 月 31 日总辐射、地面反射率、净辐射、地 面有效辐射日平均强度的年变化曲线, 图中“ +++ ”表示极夜和极昼期. 极夜期间总辐射和 地面吸收辐射 (短波净辐射) 均为 0 , 而极昼期则是极地获取太阳辐射能的主要时段. 在中山 站地区极昼期间到达地面的总辐射量为 $1506 \mathrm{MJ} / \mathrm{m}^{2}$, 地面吸收辐射为 $1127 \mathrm{MJ} / \mathrm{m}^{2}$, 分别占全 年总辐射 $\left(3759 \mathrm{MJ} / \mathrm{m}^{2}\right)$ 和地面吸收辐射 $\left(2500 \mathrm{MJ} / \mathrm{m}^{2}\right)$ 的 $40 \%$ 和 $45 \%$ 。

极尽期间实测总辐射瞬时通量极大值为 $1095 \mathrm{~W} / \mathrm{m}^{2}$ (1990 年 12 月 5 日), 接近我国中纬 度平原地区上测得的瞬时极值 $\left(1103 \mathrm{~W} / \mathrm{m}^{2}\right) .1979$ 年日本南极瑞穗站也曾观测到类似的 总辐射瞬时通量极大值 ${ }^{2}$. 南极地区总辐射瞬时通量极值是在夏季中午前后, 满天为积状云, 日面未被遮蔽的情况下出现的, 与青藏高原地区夏季总辐射瞬时值大于太阳常数时的云和日 面状况相同. 在我国青藏高原地区总辐射大于太阳常数的现象并不罕见, 它通常出现在海拔 $2000 \mathrm{~m}$ 以上地区, 是中纬度高山地区由云造成的太阳辐射再分配的结果 ${ }^{[3]}$. 南极洲有世界上 面积最大的高原, 但海拔 $2000 \mathrm{~m}$ 以上的地区大都在 $70^{\circ} \mathrm{s}$ 以南, 夏至地方时中午的最大太阳高 度角不超过 $44^{\circ}$, 即使不考虑太阳辐射在大气中的衰减及云的影响, 到达地面水平面的直接辐 射最大只有 $950 \mathrm{~W} / \mathrm{m}^{2}$, 仅为太阳常数 $\left(1367 \mathrm{~W} / \mathrm{m}^{2}\right)$ 的 $69 \%$, 因此在南极高原上不可能出现 如青藏高原那样瞬时总辐射大于太阳常数的现象.

图 3 给出了极昼期间总辐射、净辐射和地面有效辐射的平均日变化. 极昼期间,总辐射存 在着明显的日变化, 变化曲线接近于二项分布, 曲线变化平缓而连续, 与中低纬度地区的倒 “U”型分布有明显的不同. 极夜期间总辐射为 0 , 无变化.

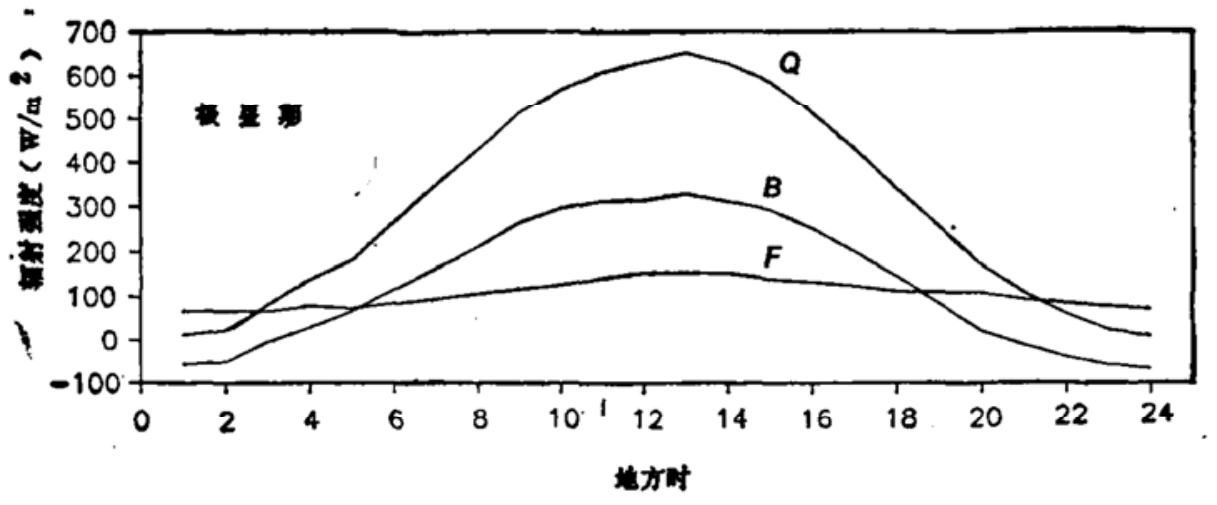

图 3 极昼期间辐射特征的日变化

\section{2. 净喓射 $B$}

净辐射和温度年变化的特点相同, 具有短暂夏季 (pointed summer) 和平缓、无心冬天 (coreless winter) 的变化特点. 在极夜开始前, 日平均净辐射早已为负值, 4-8 月的月平均 净辐射强度在 -40 到 $-55 \mathrm{~W} / \mathrm{m}^{2}$ 范围内变化, 整个极夜期间, 无明显的低值, 显示出“无心” 
的变化特点; 极夜结束后净辐射仍为负值, 仅在极昼开始前不久的 10 月日净辐射才转为大于 0 , 并在夏至前后出现净辐射日平均强度的全年极值 (图 2). 中山站地区净辐射年总为 369 $\mathrm{MJ} / \mathrm{m}^{2}$, 其中极昼期间的净辐射总量为 $622 \mathrm{MJ} / \mathrm{m}^{2}$, 是年总量的 $169 \%$; 在极夜期间地表丧失热 量,净辐射总量为 $-233 \mathrm{MJ} / \mathrm{m}^{2}$,极夜期的辐射能亏损由极昼期间的辐射能剩余来补偿.

在极夜期间净辐射受天气影响, 日际变化很大, 且有时可以出现净辐射强度大于 0 的现 象. 例如, 在 7 月 6 日中山站日平均温度较前一天丹高了 $13.6^{\circ} \mathrm{C}$, 该日的净辐射强度为 $+11.1 \mathrm{~W} / \mathrm{m}^{2}$, 而 7-9 日则分别降至 $-32 、-67$ 和 $-103 \mathrm{~W} / \mathrm{m}^{2}$; 在 7 月 15 日由于极地冷高压 响, 该日净辐射 $-131 \mathrm{~W} / \mathrm{m}^{2}$, 而次日则为 $-53 \mathrm{~W} / \mathrm{m}^{2}$, 日际变化达 $78 \mathrm{~W} / \mathrm{m}^{2}$.

极昼期间净辐射的日变化型式与总辐射相近, 有明显的日变化, 子夜前后为负值, 净辐射 值二次改变符号的时间大致为 3 时及 20 时 (图 3). 极夜期间净辐射的日变化很小.

\section{3. 地面有效辐射 $\boldsymbol{F}$}

地面有效辐射是各辐射分量中年变化幅度最小的一个 (图 2). 极昼期间地面有效辐射日 平均强度为 $106 \mathrm{~W} / \mathrm{m}^{2}$, 极夜期间为 $47 \mathrm{~W} / \mathrm{m}^{2}$, 变化幅度 $59 \mathrm{~W} / \mathrm{m}^{2}$, 而相应的总辐射及净辐射在 极尽和极夜期间日平均强度的变化幅度却为 $317 \mathrm{~W} / \mathrm{m}^{2}$ 及 $177 \mathrm{~W} / \mathrm{m}^{2}$. 地面有效辐射日平均强 度基本上全年都大于 0 ,地表总是用长波净辐射的方式向大气提供热量,使地面降温. 中山站 地区地面有效辐射年总量为 $2132 \mathrm{MJ} / \mathrm{m}^{2}$, 其中极昼期为 $505 \mathrm{MJ} / \mathrm{m}^{2}$, 极夜期为 $233 \mathrm{MJ} / \mathrm{m}^{2}$, 分 别占年总量的 $24 \%$ 及 $11 \%$.

极昼期间地面有效辐射的平均日变幅为 $89 \mathrm{~W} / \mathrm{m}^{2}$, 比净辐射的 $395 \mathrm{~W} / \mathrm{m}^{2}$ 和总辐射的 $643 \mathrm{~W} / \mathrm{m}^{2}$ 振幅都要小 (图 3). 在极夜期间地面有效与净辐射数值相等, 符号相反, 平均日变 化幅度仅为 $4 \mathrm{~W} / \mathrm{m}^{2}$.

\section{参文献}

[1] 下林根、陆龙㫵、贾朋群,南极研究,3(1991),4: 42-53.

[2] Yamanouchi, T. et al., Mem. Natt. Inst. Polar Res., Spec. Issue, 19 (1981), 27 -39.

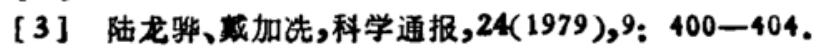

